\title{
Consistency of Peak Fat Oxidation Rates During Treadmill Ergometry: A Pilot Protocol and Methodological Elaboration
}

\author{
Raul De Souza Silveira ${ }^{1 *}$, Christoph Otto $^{1}$ and Juliane Heydenreich ${ }^{2}$ \\ ${ }^{1}$ Department of Sports Medicine \& Sports Orthopedics, University of Potsdam, Germany \\ ${ }^{2}$ Institute of Sport Science (ISSUL), Faculty of Biology and Medicine, University of Lausanne, Switzerland
}

Submission: May 11, 2017; Published: May 30, 2017

*Corresponding author: Raul De Souza Silveira, Department of Sports Medicine\& Sports Orthopedics, University of Potsdam, Germany,| Tel: +49-157-7636-5967; Email: desouzas@uni-potsdam.de

\begin{abstract}
Introduction: Maximizing fat oxidation is currently a major target in endurance sports. The aim of the present study was therefore, to (1) determine if a cycle ergometry protocol adapted to a treadmill investigational setting, would elicit potential peak fat oxidation rates; (2) Verify if these recorded variables were also maintainable throughout an endurance exercise bout.

Methods: Six healthy and recreationally active adult runners $\left(27 \pm 2.8 \mathrm{y} ; 1.72 \pm 0.10 \mathrm{~m} ; 70 \pm 17 \mathrm{~kg}, 23 \pm 2\left(\mathrm{~kg} / \mathrm{m}^{2}\right)\right.$, were examined. Subjects performed 3 different running protocols on a treadmill ergometer. For every test, breath-by-breath analysis was used to monitor metabolic activity and determine fat oxidation rates.

Results: Peak fat oxidation rates occurred at different stages of the test for the majority of subjects (i.e. stage 1 for subject $4(0.55 \mathrm{~g} / \mathrm{min})$, stage 6 for subjects $6(0.34 \mathrm{~g} / \mathrm{min})$, stage 2 for subjects 1 and $5(0.55 \& 1.31 \mathrm{~g} / \mathrm{min}$, respectively) and stage 5 for subjects 2 and $3(0.60 \& 0.56 \mathrm{~g} /$ min respectively). At the endurance test, subjects $2(0.56 \pm 0.07 \mathrm{~g} / \mathrm{min}), 3(0.48 \pm 0.13 \mathrm{~g} / \mathrm{min})$, and $6(0.38 \pm 0.05 \mathrm{~g} / \mathrm{min})$ achieved superior mean peak fat oxidation rates when compared to the previous test. The opposite was observed for subjects $1(0.20 \pm 0.05 \mathrm{~g} / \mathrm{min}), 4(0.26 \pm 0.05 \mathrm{~g} /$ $\min )$ and $5(1.05 \pm 0.15 \mathrm{~g} / \mathrm{min})$.
\end{abstract}

Conclusion: At this stage, clear methodological impairments still need to be improved before estimations of peak fat oxidation can be used as a reliable training prescription tool.

Keywords: Peak fat oxidation; Running; Pilot study

\section{Introduction}

Investigations of the physiological and metabolic responses that are produced by the human body as a result of resistance training are a common field of study in sports medicine centers around the world [1]. Some of the most established methods to evaluate energy expenditure during exercise take advantage of techniques like close- and open-circuit spirometry or more specifically, indirect calorimetry [2,3]. Every time an alike approach is implemented, gas-exchange variables associated to blood lactate parameters will help identify the physiological and metabolic strategies used by human body in order to accomplish a given exercise task [4-6]. In this regard, an often-investigated topic in exercise-physiology, involves the maximization of fat oxidation for endurance training purposes. Hereby, the current demands of professional and healthoriented athletic training require a thorough understanding of the fine points involving the human fat metabolism $[1,7]$.
Peak fat oxidation rates in professional and recreational sport activities could be profitable in many ways. For instance, in long distance sports like marathon or cycling events, it is of foremost importance to optimize the use of fat instead of relying solely on glycolytic pathways. This in turn would theoretically promote the saving of more readily available energy sources for the deciding moments of a competition (e.g. a sprint towards the end line). For health-oriented purposes, exercise protocols enabling the establishment of relative intensities for peak fat oxidation ( Fat $_{\text {peak }}$ ) could result for example, into more efficient weight control interventions [3]. Still, the exact exercise mechanisms/intensities allowing greater utilization of fatty acids for energy metabolism are less clear [8].

In order to address some of these investigational demands, scientists have been taking profit from cycle and 
treadmill spiroergometry protocols, which are widely used in laboratory settings $[8,9]$. In general, when combining any of these assessment methods to a breath-by-breath gas-exchange analysis, reliable and valid markers on a variety of metabolic parameters (e.g. oxygen uptake $\left(\mathrm{VO}_{2}\right)$, carbon dioxide output $\left(\mathrm{VCO}_{2}\right)$, peak oxygen uptake $\left(\mathrm{VO}_{2 \text { peak }}\right)$ respiratory exchange ratio (RER), etc.) can be obtained $[4,10,11]$.

However, when it comes to the estimation of absolute fat oxidation rates (g/min) or Fatpeak (e.g. as \% of $\mathrm{VO}_{2 \text { peak }}$ ), there are different physiological and ergogenic responses that remain questionable [12]. For instance, the study group of Achten $[13,14]$ reported higher rates of fat oxidation during running compared to cycling. As an attempt to physiologically explain this phenomenon, the authors conclude that during running more muscle fibers will be fully recruited, resulting into an overall increase in energy substrate consumption. Hence, higher fat oxidation rates are more likely to occur during running. This is in fact a plausible explanation, which clarifies the general physiological aspects concerning the body's response to two different kinds of exercise stimulus. However, it must be noticed that Fatpeak $\left(\%\right.$ of $\left.\mathrm{VO}_{\text {2peak }}\right)$ did not differ significantly between treadmill and cycle ergometry trials. Consequently, the researchers acknowledge the necessity of having further trials, that will eventually assess the exact mechanisms behind the differences in fat metabolism whenever performing a treadmill or cycling exercise protocol.

Other concerns around peak fat oxidation estimations, address directly the validity and reliability aspects, which are part of the different investigational protocols (i.e. validity of measured metabolicparametersand reliability of the performed exercise protocol). In order to better elucidate this problem, Meyer et al. [3] report a high intra individual variability during cycle ergometry while estimating Fat $_{\text {peak }}$. Ultimately, it has been generally stated by the authors, that Fat ${ }_{\text {peak }}$ assessments using the current available testing protocols, do not provide reliable values for exercise prescription.
All of the presented facts highlight the necessity of more in depth methodological discussions. Since, only when rigorous standardized procedures have been established, will peak fat oxidation estimations become a useful tool for training prescription and further scientific evaluations [3]. Despite some of these inherited problems, it must be reaffirmed that the estimations of absolute peak fat oxidation rates and its relative exercise intensities, is a broadly practiced procedure even though many of the currently available assessment protocols have not been fully accredited $[3,7-8,13,14]$.

At this stage, it must be noted that this current investigation has been conducted, partially as a preliminary (pilot) trial in order to develop a valid and reliable protocol that assesses peak fat oxidation rates and the derived exercising intensities during treadmill ergometry running. A subsequent and adapted protocol shown to be valid and reliable has then been developed, partly based on the current findings, and respectively published elsewhere [15]. Therefore the aims of the present study were to [1] determine if a cycler gometry protocol adapted to a pilot treadmill running protocol, would elicit higher rates of fat oxidation (i.e. potential peak fat oxidation rates and Fat ${ }_{\text {peak }}$ variables); [2] verify the stability of these estimated variables throughout a continuous endurance running bout at the identified running velocity where peak fat oxidation rates were recorded (i.e. $\mathrm{V}_{\mathrm{PFO}}$ ).

\section{Methods}

\section{Subjects}

Six healthy and recreationally active adult runners voluntarily took part in the present investigation. The study was conducted in accordance with the declaration of Helsinki. The ethics committee from Potsdam University approved the study and participants gave their written informed consent after receiving detailed information about the investigational protocol and aims. Inclusion criterion was $\geq 2 \mathrm{~h}$ of training per week. The participant's anthropometric and training data are given in Table 1.

Table 1: Anthropometric and training data from all subjects.

\begin{tabular}{|c|c|c|c|c|c|}
\hline $\begin{array}{c}\mathbf{N}^{\circ} \text { of Subjects \& } \\
\text { Gender }\end{array}$ & Age (y) & Height (m) & Weight (kg) & BMI (kg/m $\mathbf{m}^{\mathbf{2}}$ & Training (h/w) \\
\hline 2 males/4 females & $27 \pm 2.8$ & $1.72 \pm 0.10$ & $70 \pm 17$ & $23 \pm 2$ & $3 \pm 1$ \\
\hline
\end{tabular}

\section{Investigational design}

All examinations were conducted at the University's Outpatient Clinic. At day 1, a full medical check (anamnesis, anthropometrical assessment, physical examination, resting ECG) was carried out preceding the first exercise appointment as recommended by the German Federation for Cardiovascular Prevention and Rehabilitation [16]. After receiving clearance from the medical department, subjects performed 3 different running protocols on a treadmill ergometer $(\mathrm{H} / \mathrm{P} /$ Cosmos Pulsar Graphics. 2005®, Germany). The execution of these protocols was separately distributed over 3 consecutive days. Investigations took place in the morning with subjects always running at the same predetermined time (start of the exercise between 7:00 and 10:00am). Participants were asked to refrain from sport activities 24 hours prior to each measurement session. For control purposes, food intake was recorded the day prior to each of the running bouts. However, data analysis did not account for possible dietary influences in substrate oxidation patterns, nor upon physical performance, and therefore will not be reported. On days 2 and 3, participants were additionally requested to undertake an overnight fast 
and remain in a fasted state until the completion of each exercise bout (only water allowed). For every test, a breath-bybreath Metamax 3B system (Cortex Biophysik GmbH. Leipzig, Germany) was used to monitor metabolic activity. This mobile metabolic analyzer was calibrated at the beginning of each exercise session in accordance to the specific manufacturer's guidelines.

Day 1-Stepwise incremental test: This baseline test consisted of a stepwise incremental running bout until volitional exhaustion. The initial stage of $6 \mathrm{~km} / \mathrm{h}$, stage increments of $2 \mathrm{~km} / \mathrm{h}$ and stage duration of 3 minutes were defined to exhaust subjects in not less than 4 stages [3] Lactate concentrations were measured in between stages from capillary blood samples taken from the hyperemized ear lobe (Biosen S line, EKF diagnostic GmbH. Magdeburg, Germany). Subsequently, the following parameters were determined. The velocities at the aerobic threshold $\left(\mathrm{V}_{\mathrm{LT}}\right)$ [17] and RER of 1.00 $\left(\mathrm{V}_{\mathrm{RER}}\right)$, as well as $\mathrm{VO}_{\text {2peak. }}$

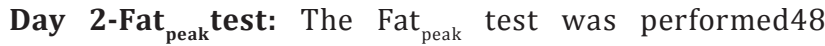
hours after the maximal incremental test. This sub maximal incremental bout lasted $30 \mathrm{~min}$, i.e. 10 stages of $3 \mathrm{~min}$ [14], and was designed on an individualized basis, based on the recorded gas-exchange and blood lactate variables from each participant [3]. The starting velocity was set at $\mathrm{V}_{\mathrm{LT}}$ while the end velocity was $V_{\text {RER }}$. Therefore, to obtain 10 stages of equal increment, the difference between end-and start-velocity needs to be divided by 9 (i.e. $\left(\left(V_{R E R}-V_{L T}\right) \div 9=\right.$ increment)). Before officially starting the test, a 3 min warm up phase at $80 \% \mathrm{~V}_{\mathrm{LT}}$ was implemented to stabilize cardiopulmonary parameters and reduce possible breathing artifacts that may arise at the beginning of exercise calorimetry $[18,19]$. Subsequently, the following parameters were determined: peak fat oxidation $(\mathrm{g} / \mathrm{min}), \mathrm{V}_{\mathrm{PFO}}(\mathrm{km} / \mathrm{h})$ and Fat $_{\text {peak }}\left(\%\right.$ of $\left.\mathrm{VO}_{2 \text { peak }}\right)$.

Day 3-endurance test at $\mathbf{V}_{\mathrm{PFO}}$ : The protocol comprises a total test length of 45 minutes and was continuously performed at $\mathrm{V}_{\mathrm{PFO}}$. Time markers were placed every 5 minutes, to keep track of the overall fat oxidation activity.

\section{Gas-exchange data and statistics}

After a plausibility check, gas-exchange data was analyzed using the software Metasoft 3, version 3.9. VO2 ${ }_{\text {peak }}$ was defined as the highest 30 seconds average value during the first incremental test. For the Fatpeak test, fat oxidation rates were calculated from $\mathrm{VO}_{2}$ and the non-protein RER according to Péronnet [20]. Gas-exchange data was viewed with time interval of 10 seconds and averaged over the last 30 seconds of each stage. By applying a third polynomial (P3) function (Prism 6, Graph Pad Software Inc.), a graphic depiction of fat oxidation rates as a function of exercise intensity was created for each individual and used to determine peak fat oxidation, $\mathrm{V}_{\mathrm{PF} 0}$, Fat ${ }_{\text {peak }}$ [1]. All of the analyzed parameters are descriptively reported as individual values, range and mean \pm standard deviation (SD). Statistical analysis was performed using Microsoft Excel 2011.

\section{Results}

\section{Stepwise incremental test}

Baseline performance data are presented in Table 2.

Table 2: Overview of individual values for VO2peak, VLT and VRER.

\begin{tabular}{|c|c|c|c|}
\hline Subject $\mathbf{N}^{\circ}$ & $\begin{array}{c}\text { VO2 } \\
\text { min/kg) } \\
\mathbf{m i n} / \mathbf{k g})\end{array}$ & $\left.\mathbf{V}_{\text {LT }} \mathbf{( k m} / \mathbf{h}\right)$ & $\mathbf{V}_{\text {RER }}(\mathbf{k m} / \mathbf{h})$ \\
\hline 1 & 42 & 6.07 & 11.6 \\
\hline 2 & 42 & 6.04 & 10.6 \\
\hline 3 & 55 & 7.26 & 14.9 \\
\hline 4 & 51 & 7.67 & 12.9 \\
\hline 5 & 53 & 8.65 & 15.3 \\
\hline 6 & 40 & 6.04 & 10.8 \\
\hline
\end{tabular}

Table 3: Overview of interpolated parameters during the Fatpeak test as well as mean fat oxidation values during the endurance test at $V_{P F O}$

\begin{tabular}{|c|c|c|c|c|c|}
\hline Subject $N^{\circ}$ & $\begin{array}{l}\text { Peak fat oxidation } \\
\text { (stage) }\end{array}$ & $\mathrm{V}_{\mathrm{PFO}}(\mathrm{km} / \mathrm{h})$ & Fat $_{\text {peak }}\left(\%\right.$ of $\left.V O_{2 \text { peak }}\right)$ & $\begin{array}{l}\text { Peak fat oxidation } \\
\qquad(\mathrm{g} / \mathrm{min})\end{array}$ & $\begin{array}{l}\text { Mean fat oxidation during } \\
\text { endurance test at } V_{P F O}(g / m i n)\end{array}$ \\
\hline 1 & 2 & 7.4 & $69 \%$ & 0.36 & $0.20 \pm 0.05$ \\
\hline 2 & 5 & 7.2 & $73 \%$ & 0.51 & $0.56 \pm 0.07$ \\
\hline 3 & 5 & 9.4 & $63 \%$ & 0.44 & $0.48 \pm 0.13$ \\
\hline 4 & 1 & 7.7 & $58 \%$ & 0.54 & $0.26 \pm 0.05$ \\
\hline 5 & 2 & 8.7 & $69 \%$ & 1.31 & $1.05 \pm 0.15$ \\
\hline 6 & 6 & 7.7 & $52 \%$ & 0.28 & $0.38 \pm 0.05$ \\
\hline
\end{tabular}


Fat ${ }_{\text {peak }}$ test \& endurance test at $\mathbf{V}_{\mathrm{PFO}}$ : As presented in Table 3, stages where peak fat oxidation was detected ranged from 1 to 6. Likewise, range values for $\mathrm{V}_{\mathrm{PFO}}$, Fatpeak and peak fat oxidation went from 7.2 to $9.4 \mathrm{~km} / \mathrm{h}, 52$ to $73 \%$ of $\mathrm{VO} 2_{\text {peak }}$ and 0.28 to $1.31 \mathrm{~g} / \mathrm{min}$ respectively. Mean fat oxidation during the endurance test at $\mathrm{V}_{\mathrm{PFO}}$ ranged from $0.20 \pm 0.05$ to $1.05 \pm 0.15$. Individual fat oxidation values during the endurance test at each of the 5 minutes marker-points are displayed in Figure 1.

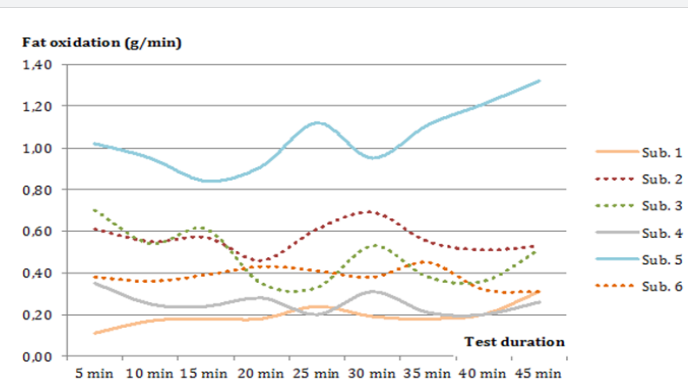

Figure 1: Fat oxidation values from all participants throughout the endurance test at $V_{\text {PFO }}$

Straight lines: subjects that did not consistently achieve the estimated peak fat oxidation rates.

Doted lines: subjects that consistently achieved or even surpassed the estimated peak fat oxidation rates.

\section{Discussion}

The current pilot investigation assessed the estimation of potential peak fat oxidation rates and Fatpeak variables in 6 healthy and recreationally active adult runners. Additionally, this investigation aimed in verifying the stability of these estimated variables throughout a continuous endurance running bout at the identified running velocity where peak fat oxidation rates were recorded.

The observed results displayed a general inconsistency amongst the investigated subjects. The initial incremental test provided a good overall picture from the average physical conditioning of the investigated subjects. Hereby and despite comparable training regimens, 3 subjects displayed overall better performances at this first stage of examinations. Nonetheless, as the current investigational design is individually constructed for each participant, these results had no impact when establishing the exercise intensities (i.e. stage increment) composing the Fat ${ }_{\text {peak }}$ tests. The starting and end velocity of the test were implemented according to Meyer (2009) [3], in order to (in physiological terms) cover the realistic range of fat oxidation kinetics. Here, the aerobic threshold can be regarded as the upper limit for regenerative training [17], while a running speed inducing a RER $=1.00$ denotes, by definitions of indirect calorimetry, an exclusive energy supply from carbohydrate metabolism [3].

Despite all these methodological standardization, results yielded from the Fatpeak tests revealed random peak fat oxidation patterns among subjects. Not only was the stage where peak fat oxidation rates occurred generally different for all subjects, but the equivalent intensity $\left(\mathrm{Fat}_{\text {peak }}\right.$ ) also varied by up to $21 \%$. Nevertheless, this variability as underlined in a secondary investigation [15], seems to be in agreement with what previous investigation have shown [13,21-23]. Still, currently one reason for early peaks in fat oxidation was most likely the duration of the warm up phase (i.e. $3 \mathrm{~min}$ at $80 \%$ from $\mathrm{V}_{\mathrm{LT}}$ ), which was probably too short in order to fully stabilize respiratory activity and avoid the recording of primed metabolic variables (i.e. a fluctuation in $\mathrm{VO}_{2}$ and $\mathrm{VCO}_{2}$ while the body adapts to a given exercising mode/intensity) [24].

This in turn, could partly explain why subjects 1,4 and 5 had peak fat oxidation recordings between stages 1 and 2 . Another possible reason justifying peak fat oxidation values in the early stages of the test would be the warm up intensity. It could be argued that the velocity (in spite of being under $\mathrm{V}_{\mathrm{LT}}$ ) was too high for the recruited participants (i.e. in relation to their physical fitness) in order to steadily increase fat oxidation rates.

Additionally and as previously above-mentioned, one other major aspect relates to the inconsistency of the computed variables for Fat ${ }_{\text {peak }}$ estimations. At this stage, the observed variability impairs sound recommendations for training prescription at both absolute and relative intensities. This variability ultimately reflects the fluctuation of fat oxidation rates, which was perceived during the endurance test. Here 3 subjects were not able to achieve average fat oxidation rates that were comparable to the ones recorded during the previous Fat $_{\text {peak }}$ test. Conversely, all remaining participants had higher average rates off at oxidation when comparing to the previous test. At first sight, these clear differences in oxidation patterns could be a direct consequence from the arbitrary respiratory values recorded, as well as the physiological and mechanical delineations used while establishing $\mathrm{V}_{\mathrm{PFO}}$

Moreover, as day-to-day variability calculations were not implemented in the current study, inter- and intra-subject variability for peak fat oxidation and Fat ${ }_{\text {peak }}$ estimations would still need to be revealed by appropriate inferential means. In spite of all, the implemented velocity during the endurance test could at least assure constant rates of fat metabolism throughout the whole 45 minutes of exercise. Furthermore, none of the subjects extrapolated the barrier where fat oxidation becomes irrelevant (i.e. RER=1). Still, prior to the

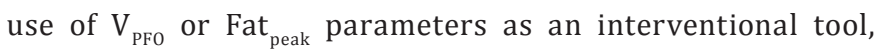
again, it is of foremost importance to first develop a reliable and valid exercise protocol, as well as establish the day-to-day variability for all relevant variables [15].

Consequently, future studies should try to improve the impairments reported in this current investigation. The focus can be directed towards two main aspects, 
1) The correct implementation of the warm up phase before beginning with a Fat ${ }_{\text {peak }}$ test (i.e. increasing the duration and adapting the intensity of the warm up to cohort needs, in order to evoke steady-state respiratory parameters.

2) Thoroughly control all of the external features that could have a direct influence on the measurement of fat metabolism (e.g. pre-exercise nutrition, physical conditioning, and time of the day, equipment and laboratory setting and so on). If all significant variables are successfully controlled and standardized, it is very likely that a coherent exercise protocol can be developed. Only then, the relevance of peak fat oxidation for training purposes can be plausibly assessed

\section{Conclusion}

Due to an obvious variability in peak fat oxidation estimations during the Fat ${ }_{\text {peak }}$ tests and a fluctuation in the fat oxidation curves during the endurance test, no consistent exercise protocol could be verified. At this stage, clear methodological impairments still need to be improved before estimations of peak fat oxidation can be used as a reliable training prescription tool.

\section{References}

1. Stisen AB, Stougaard O, Langfort J, Helge JW, Sahlin K, et al. (2006) Maximal fat oxidation rates in endurance trained and untrained women. Eur J Appl Physiol 98(5): 497-506.

2. Clark N (2008) Sports Nutrition Guidebook. ( $4^{\text {th }}$ edn), Versa Press, USA.

3. Meyer T, Folz C, Rosenberger F, Kindermann W (2009) The reliability of fat. Scand J Med Sci Sports 19(2): 213-221.

4. Macfarlane DJ, Wong P (2012) Validity, reliability and stability of the portable Cortex Metamax 3B gas analysis system. Eur J Appl Physiol 112(7): 2539-2547.

5. Perry J (2003) Ganganalyse. (1 ${ }^{\text {st }}$ edn), Urban \& Fischer, Germany.

6. Achten J, Jeukendrup AE (2004) Relation between plasma lactate concentration and fat oxidation rate over a wide range of exercise intensities. Int J Sports Med 25(1): 32-37.

7. González HC, Galilea PA, González de Suso JM, Drobnic F, Escanero JF (2007) Maximal lipidic power in high competitive level triathletes and cyclists. Br J Sports Med 41(1): 23-28.

8. Gabriel HH, Meyer T, Auracher M, Scharhag J, Kindermann W (2003) Metabolic profile of $4 \mathrm{~h}$ cycling in the field with varying amounts of carbohydrate supply. Eur J Appl Physiol 88(4-5): 431-437.
9. González HC (2011) Maximal fat oxidation rate and cross-over point with respect to lactate thresholds do not have good agreement. Int J Sports Med 32(5): 379-385.

10. Astorino TA, White AC (2010) Assessment of anaerobic power to verify $\mathrm{VO}_{2 \max }$ attainment. Clin Physiol Funct Imaging 30(4): 294-300.

11. Medbo JI, Mamen A, Welde B, von Heimburg E, Stokke R (2002) Examination of the Metamax I and II oxygen analysers during exercise studies in the laboratory. Scand J Clin Lab Invest 62(8): 585-598.

12. Vogler AJ, Rice AJ, Gore CJ (2010) Validity and reliability of the Cortex MetaMax3B portable metabolic system. J Sports Sci 28(7): 733-742.

13. Achten J, Jeukendrup AE (2003) Maximal fat oxidation during exercise in trained men. Int J Sports Med 24(8): 603-608.

14. Achten J, Venables MC, Jeukendrup AE (2003) Fat oxidation rates are higher during running compared with cycling over a wide range of intensities. Metabolism 52(6): 747-752.

15. De Souza Silveira R, Carlsohn A, Langen G, Mayer F, Scharhag RF (2016) Reliability and day-to-day variability of peak fat oxidation during treadmill ergometry. J Int Soc Sports Nutr 13(4): 1-7.

16. Bjarnason WB, Mayer BW, Meister ER, Baum K, Hambrecht R, et al (2004) Einsatz von Kraftausdauer training und Muskelaufbau training in der kardiologischen Rehabilitation. Empfehlungen der Deutschen Gesellschaftfür Prävention und Rehabilitation von Herz Kreislaufer krankungeneV. Z Kardiol 93(5): 357-370.

17. Dickhuth HH, Yin L, Niess A, Röcker K, Mayer F, et al. (1999) Ventilatory, lactate-derived and catecholamine thresholds during incremental treadmill running: relationship and reproducibility. Int J Sports Med 20(2): 122-127.

18. Xu F, Rhodes EC (1999) Oxygen uptake kinetics during exercise. Sports Med 27(5): 313-327.

19. Vogler AJ, Rice AJ, Gore CJ (2010) Validity and reliability of the Cortex Meta Max 3B portable metabolic system. J Sports Sci 28(7): 733-742.

20. Péronnet F, Massicotte D (1991) Table of Nonprotein respiratory quotient: An update. Can J Sport Sci 16(1): 23-29.

21. Gonzalez JT, Stevenson EJ (2012) New perspectives on nutritional interventions to augment lipid utilization during exercise. Brit J Nutr 107(3): 339-349.

22. Zehnder MM, Ith R, Kreis W, Saris W, Boutellier U, et al. (2005) Genderspecific usage of intramyocellular lipids and glycogen during exercise. Med Sci Sport Exer 37(9): 1517-1524.

23. Brun JF, Jean F, Ghanassia E, Flavier S, Mercier J (2007) Metabolic training: new paradigms of exercise training for metabolic diseases with exercise calorimetry targeting individuals. Ann Readapt Med Phys 50: 528-534.

24. Meyer T, Luciia A, Earnest CP, Kindermann W (2005) A conceptual framework for performance diagnosis and training prescription from sub maximal parameters -theory and application. Int J Sports Med 26(S1): 38-48. 
This work is licensed under Creative Commons Attribution 4.0 License DOI: $10.19080 /$ NFSIJ.2017.02.555599

\section{Your next submission with Juniper Publishers will reach you the below assets}

- Quality Editorial service

- Swift Peer Review

- Reprints availability

- E-prints Service

- Manuscript Podcast for convenient understanding

- Global attainment for your research

- Manuscript accessibility in different formats ( Pdf, E-pub, Full Text, Audio)

- Unceasing customer service

Track the below URL for one-step submission https://juniperpublishers.com/online-submission.php 